\title{
POSSIBLE MECHANISM FOR TESTICULAR FOCAL NECROSIS INDUCED BY hCG IN RATS
}

\author{
Fumio CHATANI \\ Development Research Center, Pharmaceutical Research Division, Takeda Pharmaceutical Co. Ltd., \\ 2-17-85 Jusohonmachi, Yodogawa-ku, Osaka 532-8686, Japan
}

(Received May 24, 2006; Accepted June 15, 2006)

\begin{abstract}
Possible mechanisms for testicular focal necrosis induced by human chorionic gonadotropin (hCG) were examined in Fischer 344 rats. A single s.c. injection of $2000 \mathrm{IU} / \mathrm{kg}$ hCG produced focal necrosis 2 days later in testicular tissues such as the seminiferous tubules in the frontal lower part of the testis (FLPT) of 11-week-old F344/Jcl rats. This hCG-induced necrosis was suppressed by an oral treatment (concomitant or delayed by $3 \mathrm{hr}$ ) with cyclooxygenase inhibitors (indomethacin, rofecoxib) or prostaglandin (PG) receptor blocker (AA-2414). Focal necrosis was also induced by intratesticular injection of $\mathrm{PGF}_{2 \alpha}$ or $\mathrm{PGE}_{2}$ with this necrosis suppressed by previous oral treatment with AA-2414, and the $\mathrm{PGF}_{2}$ level in the testis increased $4 \mathrm{hr}$ after hCG treatment. These findings suggested that de novo synthesis of PGs beginning at 3-4 hr was responsible for induction of necrosis. No necrosis was induced by hCG in the Leydig cell-devoid testis produced by ethane dimethanesulfonate treatment. Necrosis of spontaneously-induced Leydig cell tumor mass was also induced by hCG, suggesting that Leydig cells are responsible for induction of necrosis. An injection of dye into the testicular artery and laser Doppler flowmetry revealed a continuous reduction of blood flow at the FLPT at 6-48 hr after hCG treatment; contrary to this, the upper part showed an early recovery from the reduced flow. From these results, the mechanism of the hCG-induced necrosis was concluded to be: 1) hCG stimulates Leydig cells to synthesize PGs de novo; 2) PGs induce the intratesticular arteries to contract in the FLPT; and 3) obstruction of blood flow (ischemia) for more than $12 \mathrm{hr}$ induced focal necrosis in the testis.
\end{abstract}

KEY WORDS: hCG, Rat, Testis, Necrosis, Prostaglandin, Blood flow

\section{INTRODUCTION}

hCG is widely used to stimulate Leydig cells in basic experiments in animals including rats as well as clinical therapy in humans because of its luteinizing hormone-like activity. Treatment with high-dose hCG has been reported to induce testicular necrosis in rats (van Vliet et al., 1988). The possible mechanism of this necrosis has been hypothesized to involve hCGinduced increases in prostaglandin synthesis with consequent reduced blood flow, leading to increased cell death in Wistar or SD rats (van Vliet et al., 1988; Haour et al., 1979; Widmark et al., 1986). However, the definite mechanism or necrosis site has never been defined. We previously reported that the necrosis site was restricted to the frontal lower part of the testis (FLPT), and that F344 rats were most susceptible in induction of necrosis by hCG (Chatani, 1996). The age of F344 rats was also an important factor because the testis was sensitive at 11 weeks of age but not at 8 weeks or less. In the present study, several experiments were conducted in order to clarify the mechanism of the hCGinduced testicular focal necrosis in the most susceptible 11-week-old F344 rats using several inhibitors/blockers of prostanoids, Leydig cell-devoid testis, Leydig cell tumor, and testicular blood flowmetry.

\section{MATERIALS AND METHODS}

\section{Animals \\ Male F344/Jcl rats were purchased from CLEA Japan, Inc. at 10 weeks of age and used after 1-week acclimation. Rats were housed at 1 or 2 animals/cage in metal cages at room temperature of $20-26^{\circ} \mathrm{C}$, relative}

Correspondence: Fumio CHATANI (E-mail: Chatani_Fumio@takeda.co.jp) 
F. CHATANI

humidity of 50-60\%, air exchange 8-12 times/hr, and 12-hr light/dark cycle. The animals were allowed free access to tap water and a pellet diet (CE-2, CLEA Japan, $\gamma$-ray irradiated). For the Leydig cell tumor experiment, the same strain of rats was purchased and used at 90 - 111 weeks of age. All animal experiments were conducted in accordance with the regulations of the Committee for Experiments on Animals of Takeda Pharmaceutical Company Limited.

\section{Chemicals}

Human chorionic gonadotropin (hCG, Gonatropin $^{\circledR}$ ) was purchased from Teikoku Zohki (Japan). The hCG was dissolved in saline $(2 \mathrm{ml} / \mathrm{kg}$ body weight) just before s.c. administration. The following were synthesized at Takeda Pharmaceutical Company Limited: the nonselective cyclooxygenase inhibitor (indomethacin, IN), a specific inhibitor of cyclooxygenase-2 (rofecoxib; Chan et al., 1999), the prostaglandin/thromboxane $\mathrm{A}_{2}$ receptor blocker (AA2414; Imura et al., 1990), a thromboxane $\mathrm{A}_{2}$ synthetase inhibitor (CV-4151; Imura et al., 1988), and a 5-lipoxygenase inhibitor (AA-861; Ashida et al., 1983). All of these were verified by appropriate analytic methods. They were suspended in 5\% gum arabic solution in appropriate concentrations for oral dosing. Prostaglandins $\mathrm{F}_{2 \alpha}, \mathrm{E}_{1}$ and $\mathrm{E}_{2}\left(\mathrm{PGF}_{2 \alpha}, \mathrm{PGE}_{1}\right.$ and $\mathrm{PGE}_{2}$ ) were purchased from Cayman Chem. or Wako Pure Chem. and dissolved in $10 \%$ ethanol/saline. Ethane dimethanesulfonate (selective Leydig cell destroyer, EDS) was provided by Osaka Medical College and dissolved in dimethylsulfoxide (DMSO, Wako Pure Chem.) and distilled water (1:3 in volume).

\section{Treatments}

The hCG administration and testicular histopathology procedures were very similar across the experiments.

\section{Administration}

All 11-week-old F344/Jcl rats in the treatment groups received a single s.c. injection of hCG solution at the dosage level of $2000 \mathrm{IU} / \mathrm{kg}$ in a volume of $2 \mathrm{ml} /$ $\mathrm{kg}$ at the dorsal area of the animals, and were euthanized 2 days later. The dose of $2000 \mathrm{IU} / \mathrm{kg}$ was selected from the results of the dose-response experiments (Chatani, 1996). Control rats received physiological saline only (hCG dose: $0 \mathrm{IU} / \mathrm{kg}$ ) in the same manner as the treatment groups. Dosage volumes of the solution/ suspension of hCG or agents were determined based on body weight on the dosing day. The above procedures were used unless otherwise described.

\section{Histopathology}

The right and left testes were collected at necropsy (routinely 2 days after the treatment with hCG), fixed in $10 \%$ neutral buffered formalin for 2 days or longer, transected along the testicular longitudinal plane (a frontal-dorsal plane) and embedded in paraffin. Sections with a thickness of $4 \mu \mathrm{m}$ were stained with hematoxylin-eosin (H-E) and examined microscopically, paying special attention to the necrotic seminiferous tubules. The necrosis was graded according to the area occupied by the change: necrosis occupying approximately 5,10, 20 and $40 \%$ of the longitudinal section was graded as minimum, mild, moderate and severe, and is scored as $0.5,1,2$ and 3 , respectively, according to the necrosis criteria in the previous report (Chatani, 1996). Other histopathologic changes, e.g. interstitial neutrophil infiltration, edema and multinucleated giant cell formation, were not evaluated in this mechanistic experiment.

\section{Experimental designs}

A series of experiments was designed to explore the involvement of (A) prostaglandins, (B) mediation by Leydig cells, and (C) testicular blood flow. The individual experimental designs are as follows:

\section{PG involvement}

1) Effect of prostanoid synthesis inhibitors/antagonists on hCG-induced necrosis

To test the hypothesis that PGs are involved in this necrosis, IN $(5 \mathrm{mg} / \mathrm{kg})$ was administered orally just before hCG dosing (2000 IU/kg). Rofecoxib $(10 \mathrm{mg} / \mathrm{kg}$ ) was dosed $10 \mathrm{~min}$ before hCG dosing, and AA-2414, AA-861 and CV-4151 were administered $1 \mathrm{hr}$ before hCG dosing at doses of 100, 100 and $50 \mathrm{mg} / 5 \mathrm{ml} / \mathrm{kg}$, respectively. All the inhibitors/ antagonists were suspended in 5\% gum arabic solution, and dosed once by gastric intubation. Each pair of the testes of 3 or 4 rats/group was sampled 2 days after the dosing and examined histopathologically.

2) Effect of timing of cyclooxygenase inhibition on hCG-induced necrosis

IN $(5 \mathrm{mg} / \mathrm{kg})$ was orally dosed once at $1,0.5$ or 0 hr before hCG dosing or 1, 2, 3, 4 or $6 \mathrm{hr}$ after hCG (2000 IU/kg). The testes of 3 rats/timepoint were collected 2 days after dosing and examined histopathologically.

3) Effect of timing of PG receptor blocking on hCGinduced necrosis

AA-2414 (100 mg/5 ml/kg) was dosed once 1 or 
Possible mechanism for testicular focal necrosis induced by hCG in rats.

$0 \mathrm{hr}$ before hCG dosing or 2, 4, $6 \mathrm{hr}$ after hCG dosing. The testes of 3 rats/timepoint were collected 2 days after dosing and examined histopathologically.

4) Effect of $P G$ treatment

$\mathrm{PGF}_{2 \alpha}, \mathrm{PGE}_{1}$ and $\mathrm{PGE}_{2}$, dissolved in ethanolsaline, were injected into the center of the left testis percutaneously under ether anesthesia with doses of $5 \mu \mathrm{g} / 10 \mu \mathrm{l} /$ testis and $50 \mu \mathrm{g} / 100 \mu \mathrm{l} /$ testis that corresponded to approximately 4 and $40 \mu \mathrm{g} / \mathrm{g}$ testis, respectively. The right testes received saline and served as the control. The testes of 3 rats/timepoint were collected 2 days after dosing and examined histopathologically. A pilot study revealed that necrosis occurred only at the FLPT when PG was injected at either the upper, center or lower part of the testis.

5) Effect of PG receptor blockade on PG-induced necrosis

One hr before or $1 \mathrm{hr}$ after the intratesticular injection of $5 \mu \mathrm{g} / 10 \mu \mathrm{l} /$ testis of $\mathrm{PGF}_{2 \alpha}$ (left testis) and $\mathrm{PGE}_{2}$ (right testis), AA-2414 (100 mg/kg) was administered as a single oral dose. The testes of 3 rats/group were collected and examined histopathologically.

6) PG level in the testis

To test the hypothesis that hCG stimulated increased intratesticular levels of PGs, 3 rats were treated s.c. with $1000 \mathrm{IU} / \mathrm{kg} \mathrm{hCG}$ or saline and the testes were collected $4 \mathrm{hr}$ later. The testes were homogenized with IN in methanol in $1 \mathrm{M}$ phosphate buffer, and the homogenates were kept frozen until assayed. $\mathrm{PGF}_{2 \alpha}$ was extracted with methanol chloroform by several mixing, centrifugation and filtration. $\mathrm{PGF}_{2 \alpha}$ level was measured by radioimmunoassay in Mitsubishi Kagaku BCL, Inc.

\section{Leydig cell involvement}

1) Effect of Leydig cell destruction by EDS on hCGinduced necrosis

To test the hypothesis that Leydig cells play a central role in post-hCG necrosis, EDS $(100 \mathrm{mg} / \mathrm{kg}$ in $25 \%$ DMSO in saline) or vehicle was injected i.p. to 3 or 4 rats/group according to the method of Morris et al. (1987), and $2000 \mathrm{IU} / \mathrm{kg}$ hCG or saline was administered s.c. 3 days after the EDS injection. The testes were collected 2 days after hCG dosing and examined histopathologically.

2) Necrosis of Leydig cell tumor by hCG

To use a different model of Leydig cell involvement in hCG-induced necrosis, 5 F344/Jcl rats, aged 90 or 102 weeks, were palpated to confirm the presence of spontaneous bilateral Leydig cell tumors. These rats received $2000 \mathrm{IU} / \mathrm{kg}$ hCG as a single s.c. injection. The testes were collected 2 days after dosing, sectioned longitudinally, and examined histopathologically. Six tumor-bearing rats aged 104 or 111 weeks served as the controls without any treatment.

\section{Testicular blood flow change}

1) Distribution of dye injected into the testicular artery To address the possibility that reduced blood flow might be a factor in the post-hCG necrosis, blood distribution in the testis was examined by infusing a blue dye into the testicular artery. The abdominal wall of 11-week-old rats was dissected under general anesthesia (ketamine $\mathrm{HCl} 50 \mathrm{mg} / \mathrm{kg}$ i.m. and doroperidol $2.5 \mathrm{mg} / \mathrm{kg}$ s.c.), and both the renal arteries and lower abdominal aorta were totally ligated. Saline and then $1 \%$ Evans blue solution was perfused into the testicular artery via the aorta $6 \mathrm{hr}$ after the hCG dosing with $2000 \mathrm{IU} / \mathrm{kg}$. Perfusion was continued for approximately $10 \mathrm{sec}$ up to the clear appearance of the blue color in the testicular vein on the testis surface. The testis surface was examined grossly for distribution of blue-staining, and then the animals euthanized by bleeding. Two rats were used for each 6-hr hCG group and 6-hr saline control group.

2) Distribution of liquid plastics in testicular vessels

In order to visualize the shape and relative luminal diameters of the testicular vasculature, liquid plastic casts were made of hCG-treated testes. Rats were treated as they were for the dye experiment. Saline and then red liquid silicon rubber (Microfil $^{\circledR}$, MV-117, Canton Bio-Med. Products) was perfused into the testicular artery via the aorta in 6 rats $6 \mathrm{hr}$ after $2000 \mathrm{IU} / \mathrm{kg} \mathrm{hCG}$. There were 6 saline control rats. After the infusion of the liquid rubber, the testes were removed and incubated in a high-humidity chamber for 1 day at room temperature to harden the rubber, and then passed through a graded ethanol series. They were made transparent with salicylate, cut to $3 \mathrm{~mm}$ thickness to mount in Permount ${ }^{\circledR}$ (Fisher Scientific), and the intratesticular vessels filled with the rubber in the longitudinal section of the testis were observed with a binocular microscope.

3) Measurement of testicular blood flow

Animals were anesthetized by $50 \mathrm{mg} / \mathrm{kg}$ of pentobarbital (Nembutal, i.p.) and the testes exteriorized through a scrotal incision. The tip of a laser Doppler flowmeter probe (FL-N1, Neuroscience) 
was placed at a distance of approximately 2-3 mm above the testicular surface devoid of large artery or vein, and the blood flow $1 \mathrm{~mm}$ beneath the testicular capsule near the lower and upper pole (sites showing testicular necrosis and no change, respectively) was measured for approximately $1 \mathrm{~min}$ in each of sites $1,2,4,6,10,14,19,24$ or $48 \mathrm{hr}$ after a s.c. treatment with $2000 \mathrm{IU} / \mathrm{kg} \mathrm{hCG}$. In control rats the flow was measured at 0 and $7 \mathrm{hr}$ after saline s.c. treatment. Three sites in each of the lower and upper parts (right or left testis) were measured in each of 3 rats per timepoint. The flow (relative value) was recorded on chart paper by polygraph and average blood flow calculated from maximum and minimum flow values. Oscillation magnitude (maximum flow - minimum flow) and pulse frequency (wave number in a minute) were also recorded. The mean values of these 3 parameters at each of 3 sites were compiled into an individual value for each rat and then the mean and standard deviation (S.D.) was calculated from 3 rats in each timepoint.

\section{Data-handling}

The necrosis scores of each individual testis were compiled and the mean \pm S.D. calculated using the average value of right and left testis. Statistical significance was not tested in any study because of the small number of specimens or the presence of a clear difference.

\section{RESULTS}

\section{Prostaglandins}

1. Effect of hCG treatment on testis and of prostanoid antagonists on hCG-induced necrosis (Table 1)

hCG with $2000 \mathrm{IU} / \mathrm{kg}$ induced severe necrosis (necrosis score 3.0) at the FLPT. There was no cell specificity, spermatogenic-stage specificity in the necrosis, nor any difference in the necrosis grade between the right and left testis. IN, rofecoxib or AA2414 treatments inhibited the hCG-induced necrosis completely (all score 0.0); however, AA-861 and CV4151 failed to inhibit the necrosis (score 2.5).

\section{Timing of cyclooxygenase inhibition for hCG- induced necrosis (Fig. 1)}

IN treatment $0.5 \mathrm{hr}$ before and $0-3 \mathrm{hr}$ after hCG dosing inhibited necrosis (score 0.0-0.3). IN treatment $1 \mathrm{hr}$ before and 4-6 hr after hCG gave partial protection (score 1.1-1.8), suggesting that synthesis of a sufficient amount of PG by cyclooxygenase for the induction of the necrosis began 3-4 hr after the hCG treatment.

\section{Effect of PG receptor blocking on hCG-induced necrosis (Fig. 2)}

AA-2414 treatment $1 \mathrm{hr}$ before and $4 \mathrm{hr}$ after the hCG dosing inhibited the hCG-necrosis almost completely (score 0.0-0.1); AA-2414 treatment $6 \mathrm{hr}$ after hCG dosing showed a weak effect for inhibition (score 1.3 vs. control 2.5), suggesting that the effect of PG at the $\mathrm{PG}$ receptor level began $4 \mathrm{hr}$ after the hCG treatment.

\section{PG treatment}

Intratesticular injection of PG at 5 and $50 \mu \mathrm{g} /$ tes-

Table 1. Effect of inhibitors on necrosis from hCG.

\begin{tabular}{|c|c|c|c|}
\hline \multicolumn{3}{|c|}{ compound } & \multirow{2}{*}{ necrosis score } \\
\hline \multicolumn{2}{|c|}{ 1st dose (blocker or inhibitor) } & 2nd dose & \\
\hline- & - & - & 0.0 \\
\hline- & - & hCG & $3.0 \pm 0.0$ \\
\hline Cyclooxygenase (COX) inhibitor & indomethacin & hCG & 0.0 \\
\hline COX-2 inhibitor & rofecoxib* & hCG & 0.0 \\
\hline PG receptor blocker & AA-2414** & hCG & 0.0 \\
\hline 5-lipoxygenase inhibitor & AA-861** & hCG & $2.5 \pm 0.0$ \\
\hline TXA2 synthetase inhibitor & CV-4151** & hCG & $2.5 \pm 0.0$ \\
\hline
\end{tabular}

hCG $2000 \mathrm{IU} / \mathrm{kg}$, s.c.; 0, $10 \mathrm{~min} *$ or $60 \mathrm{~min} * *$ after oral dosing of inhibitor or blocker. 3 or 4 pairs of testes (3 or 4 rats)/group. necrosis scores $0,0.5,1,2$ and $3=$ none, minimum, mild, moderate and severe necrosis, respectively. Indomethacin, $5 \mathrm{mg} / \mathrm{kg}$; rofecoxib, $10 \mathrm{mg} / \mathrm{kg}$; AA-2414, AA-861, $100 \mathrm{mg} / \mathrm{kg}$; CV-4151, $50 \mathrm{mg} / \mathrm{kg}$. 
Possible mechanism for testicular focal necrosis induced by hCG in rats.

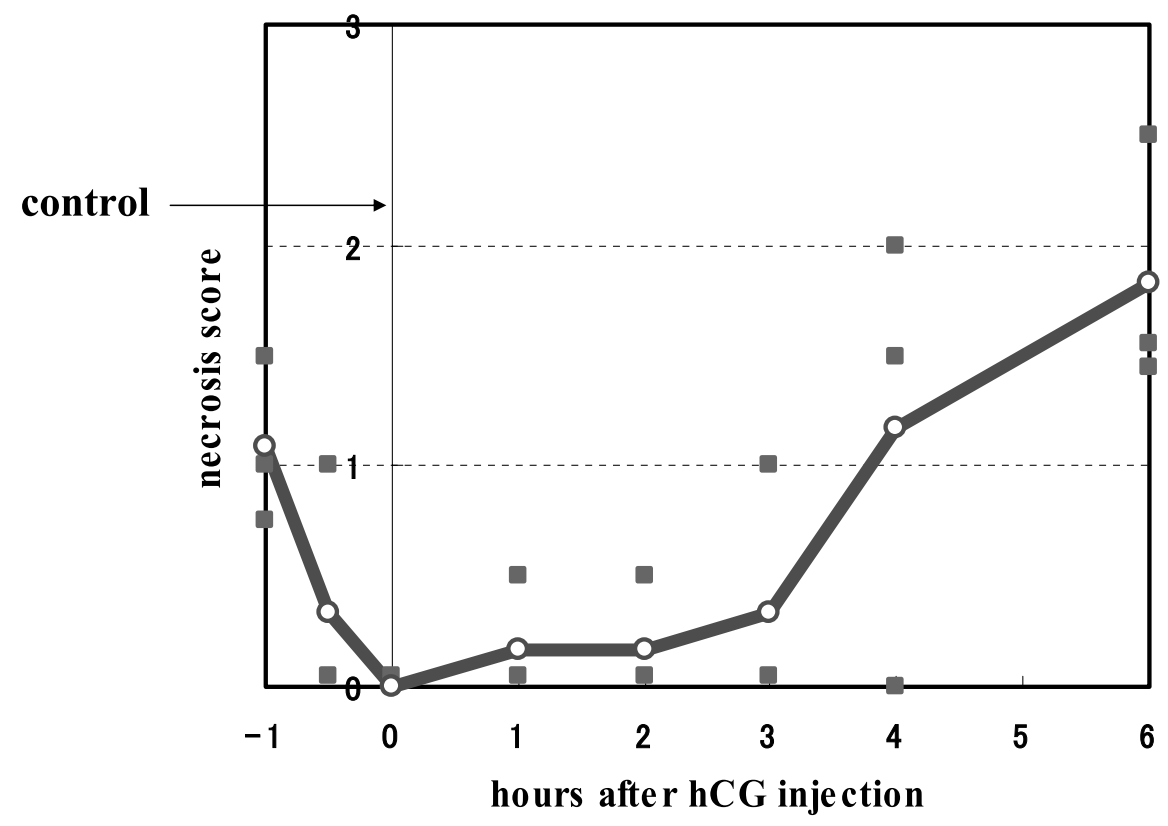

Fig. 1. Inhibition of hCG-induced testicular necrosis by indomethacin (IN). Rats received s.c. $2000 \mathrm{IU} / \mathrm{kg} \mathrm{hCG}$ followed by p.o. $5 \mathrm{mg} / \mathrm{kg} \mathrm{IN}$, and necrosis score was examined 2 days later. Induction of necrosis was suppressed by IN which was treated at $-0.5 \mathrm{hr}$ to $3 \mathrm{hr}$ after hCG dosing.

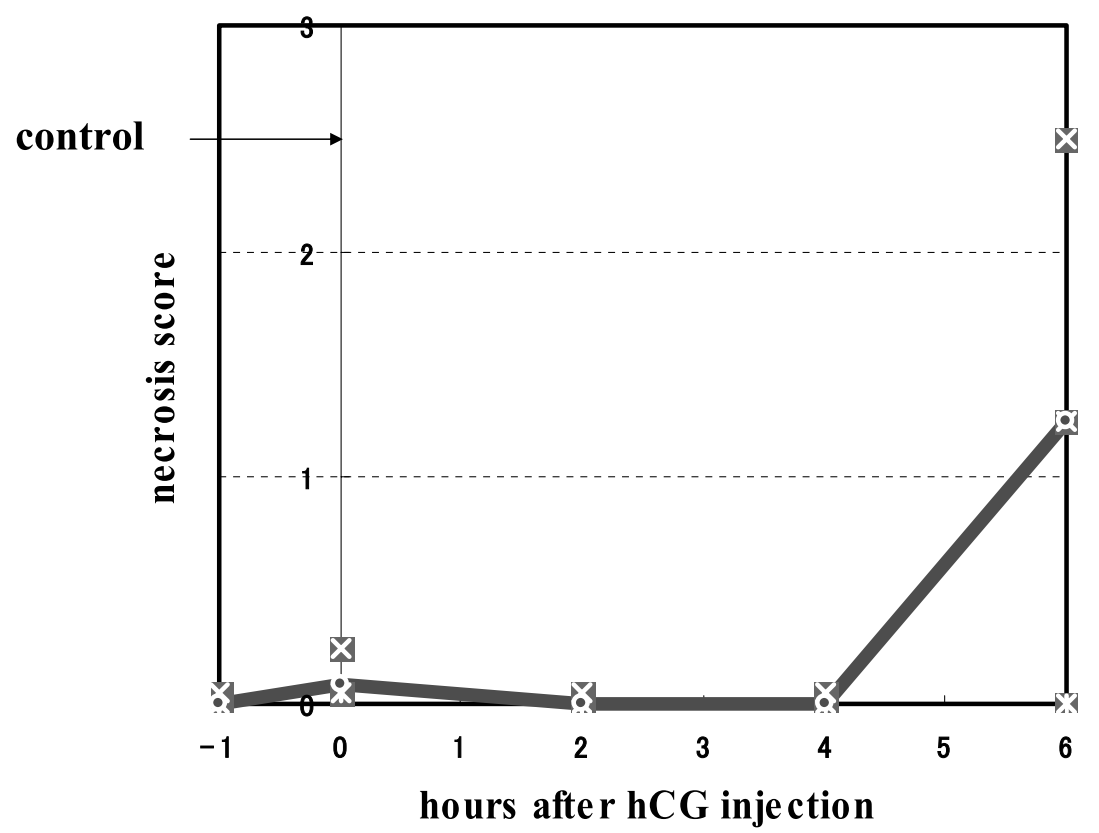

Fig. 2. Inhibition of hCG-induced testicular necrosis by AA-2414. Rats received s.c. $2000 \mathrm{IU} / \mathrm{kg}$ hCG followed by p.o. $100 \mathrm{mg} / \mathrm{kg}$ AA-2414, and necrosis score was examined 2 days later. Induction of necrosis was suppressed by AA-2414 which was treated at $-1 \mathrm{hr}$ to $4 \mathrm{hr}$ after hCG dosing. 


\section{F. CHATANI}

tis induced necrosis at the FLPT (score 1.0 and 3.0 for $\mathrm{PGF}_{2 \alpha}$, and 1.3 and 3.0 for $\mathrm{PGE}_{2}$, respectively). The histologic appearance, location and extent of necrotic change were comparable to hCG-induced necrosis. $\mathrm{PGE}_{1}$ injection induced no necrosis at either dose.

\section{PG receptor blocking for the $\mathrm{PG}$-induced necrosis (Table 2)}

Pretreatment of AA-2414 completely inhibited the necrosis induced by intratesticular injection of $\mathrm{PGF}_{2 \alpha}$ and $\mathrm{PGE}_{2}$ at $5 \mu \mathrm{g} /$ testis (score 0.0 ); treatment of AA-2414 $1 \mathrm{hr}$ after the PG injection failed to inhibit the necrosis (score 1.0 and 1.7, respectively).

\section{PG level in the testis}

Injection of hCG increased testicular $\mathrm{PGF}_{2 \alpha}$ to 4 times the control level at $4 \mathrm{hr}(55.33 \pm 28.45$ vs. 238.8 $\pm 83.62 \mathrm{ng} / \mathrm{g}$ testis).

\section{Leydig cells}

\section{Effect of Leydig cell destruction by EDS on the} hCG-induced necrosis (Table 3)

Microscopic observation confirmed that EDS treatment reduced the Leydig cell population of the testis, or stimulated their degeneration, 3 days after EDS treatment. The necrosis induced by hCG was also absent (score 0.0) from the EDS-treated group. A necrosis score of 2.3 was observed in the DMSO group (control group) without Leydig cell destruction. These data suggest that Leydig cells are essential for induction of necrosis by hCG treatment.

\section{Necrosis of Leydig cell tumor by hCG (Table 4, Photo 3)}

Diffuse necrosis of the tumor cells was observed in all 10 testes with massive Leydig cell tumors. The morphometric mean value of the necrotic area in the whole testis tissue was $48 \%$ (range: $5-95 \%$ ). The tumors around relatively large intratesticular arteries occasionally showed no necrosis. The necrotic areas were not restricted to the lower part of the testis tumor. No tumor cell necrosis was observed in any of the 12 testes in the control group.

\section{Testicular blood flow}

1. Distribution of dye injected into the testicular artery (Photo 4)

The entire testis in the saline-control group stained blue, indicating sufficient blood circulation. In hCG-treated animals, the FLPT (surrounding area of the superficially ascending bizarre testicular artery) appeared paler blue than the central or rostral parts of the testis at $6 \mathrm{hr}$ after hCG dosing, suggesting little distribution of the dye in this part.

\section{Distribution of liquid plastics in testicular vessels}

At $6 \mathrm{hr}$ after hCG dosing, no artery or arteriole in the frontal lower part of the longitudinally sectioned

Table 2. Effect of PG receptor blocker on necrosis from PG.

\begin{tabular}{|c|c|c|c|}
\hline \multicolumn{2}{|c|}{ compound } & \multicolumn{2}{|c|}{ necrosis score } \\
\hline 1st dose & 2nd dose & $\mathrm{PGF}_{2} \alpha$ & $\mathrm{PGE}_{2}$ \\
\hline PG & - & $1.0 \pm 1.0$ & $1.7 \pm 1.2$ \\
\hline PG & AA-2414 & $1.0 \pm 1.0$ & $1.7 \pm 1.5$ \\
\hline AA-2414 & PG & 0.0 & 0.0 \\
\hline
\end{tabular}

$\mathrm{PGF}_{2} \alpha$ or $\mathrm{PGE}_{2}(5 \mu \mathrm{g} / \mathrm{testis})$ was injected into the testis; AA-2414 was dosed orally at $100 \mathrm{mg} / \mathrm{kg}$.

The 2 nd dosing was conducted $1 \mathrm{hr}$ after the 1 st dosing. The mean \pm S.D. from 3 rats/group is shown.

Table 3. Effect of EDS on necrosis by hCG.

\begin{tabular}{ccc}
\hline \multicolumn{2}{c}{ compound } & necrosis score \\
\hline 1st dose & 2nd dose & \\
\hline Vehicle & Saline & 0.0 \\
EDS & Saline & 0.0 \\
Vehicle & hCG & $2.3 \pm 0.6$ \\
EDS & hCG & 0.0 \\
\hline
\end{tabular}

Ethane dimethanesulfonate (EDS) $100 \mathrm{mg} / \mathrm{kg}$ was dosed i.p. to destroy the testicular Leydig cells 3 days before s.c. $2000 \mathrm{IU} / \mathrm{kg}$ hCG dosing. Vehicle: $25 \%$ DMSO. The mean \pm S.D. from 3 or 4 rats/group is shown.
Table 4. Necrosis of Leydig cell tumors by hCG.

\begin{tabular}{l}
\hline group necrosis area (\% of tumor area) \\
\hline Control \\
hCG \\
\hline hCG $2000 \mathrm{IU} / \mathrm{kg}$ was orally dosed to aged rats having \\
bilateral testicular spontaneous Leydig cell tumors that \\
entirely replaced the testicular tissue. The necrotic area in \\
the testicular tissue area was measured morphometrically in \\
5 or 6 rats/group and expressed as the mean \pm S.D.
\end{tabular}


Possible mechanism for testicular focal necrosis induced by hCG in rats.

testis specimen was filled with red plastic, indicating a local contraction of arteries.

\section{Measurement of testicular blood flow (Fig. 3, 4 and} 5)

Control testes from untreated rats (prior to hCGdosing) showed a mean testicular blood flow to be 15 units (range 8-22; relative flow rate) with a pulsatile cycle of $8-13 / \mathrm{min}$. In the hCG-treated rats, no change in the flow was observed at $1 \mathrm{hr}$ with a slight reduction in 1 of 3 rats at $2 \mathrm{hr}$. At $6 \mathrm{hr}$ after hCG dosing, there was a marked reduction to approximately 4-7 (approximately $1 / 4-1 / 2$ of the control) in both lower and upper parts of testes from all 3 rats. The lower part (FLPT) showed a persistently low blood flow at approximately half the control value for up to $48 \mathrm{hr}$. The upper part showed a more modest reduction in the flow compared to the lower part (maximum reduction in the upper part of the testis was approximately $1 / 2$ of the pre-dosing level) which recovered to the normal level at $14 \mathrm{hr}$ although the normal pulsatile oscillations were still dampened. The flow at the rostral pole of the testis at $24 \mathrm{hr}$ was $50 \%$ higher than the pre-dosing level. The changes in the oscillation magnitude were similar in magnitude to those seen for blood flow: pulsatile oscillation disappeared completely with a flat flow 4-14 hr after hCG-dosing in both lower and upper parts, and a half-magnitude oscillation appeared thereafter in the lower part.

\section{DISCUSSION}

The possible mechanism of the testicular focal necrosis induced by s.c. injection of hCG in male F344

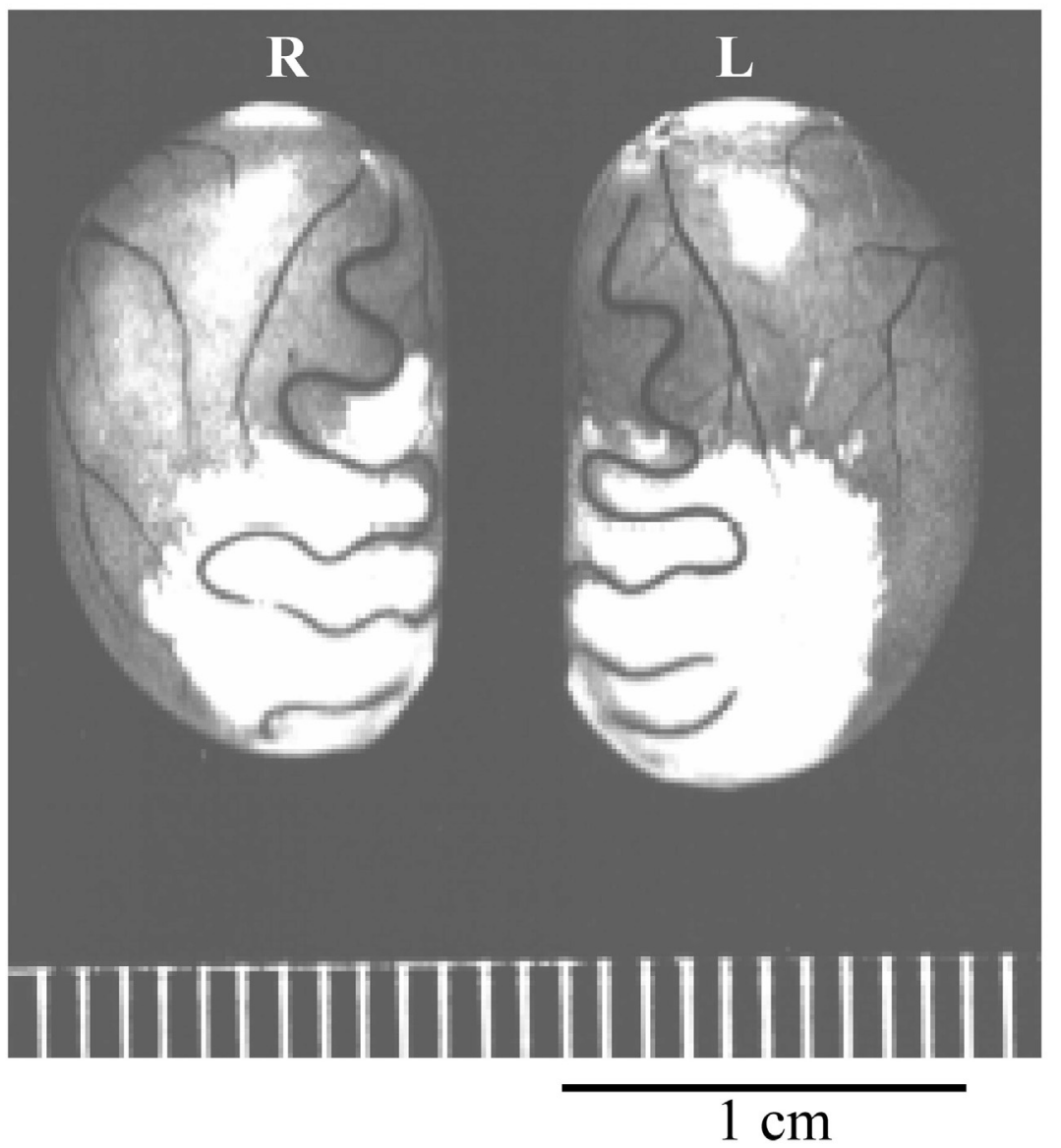

Photo 1. Macroscopic necrotic area of testes after hCG treatment. The lower parts of the testes appear white due to calcification of the tissues 4 weeks after s.c. 2000 IU/kg hCG dosing (by Chatani, 1996). 


\section{F. CHATANI}

rats was examined.

The occurrence of the focal necrosis which could be induced in the FLPT by hCG treatment was completely suppressed by concomitant treatment of PG synthetase inhibitors (nonselective COX inhibitor, IN; COX-2 selective inhibitor, rofecoxib) or PG receptor blocker (AA-2414), but not by lipoxygenase inhibitor (AA-861) or TXA 2 synthetase inhibitor (CV-4151), suggesting that $\mathrm{PGs}$ were involved in the induction of necrosis but leucotrienes or $\mathrm{TXA}_{2}$ were not. Oral treatment with IN or AA-2414 at $4 \mathrm{hr}$ after the hCG injection was still effective in the suppression of hCGinduced necrosis but the effectiveness was reduced later, indicating that the effect was occurring in the first 3-4 hr. Similar necrosis was induced by a direct intratesticular injection of $\mathrm{PGF}_{2 \alpha}$ and $\mathrm{PGE}_{2}$ but not by $\mathrm{PGE}_{1}$, and PG-induced necrosis was completely suppressed by a PG receptor blocker AA-2414. A 4-fold increase in testicular $\mathrm{PGF}_{2 \alpha}$ levels was noted at $4 \mathrm{hr}$ after hCG dosing. These results suggested that de novo synthesis of $\mathrm{PGF}_{2} \alpha$ and $\mathrm{PGE}_{2}$ by COX-2 began approximately 3-4 hr after hCG exposure, and was responsible for the induction of the necrosis via action at the PG receptor. In addition, van Vliet et al. (1988) showed a marked increase in the levels of PGs in the rat testis $6 \mathrm{hr}$ after hCG treatment in ex vivo experiment, and Haour et al. (1979) also reported a dramatic increase in the $\mathrm{PGF}_{2 \alpha}$ and $\mathrm{PGE}_{2}$ production $6 \mathrm{hr}$ after hCG stimulation in an in vitro culture system of normal Leydig cells of rats. The discrepancy in the necrosisinducing dose of the PG injected into the testis and in the concentration of PG measured in the testis may be due to a possible short half-life of PG and a continuous production of the PG in the testis after the hCG administration.

hCG treatment failed to induce necrosis in the

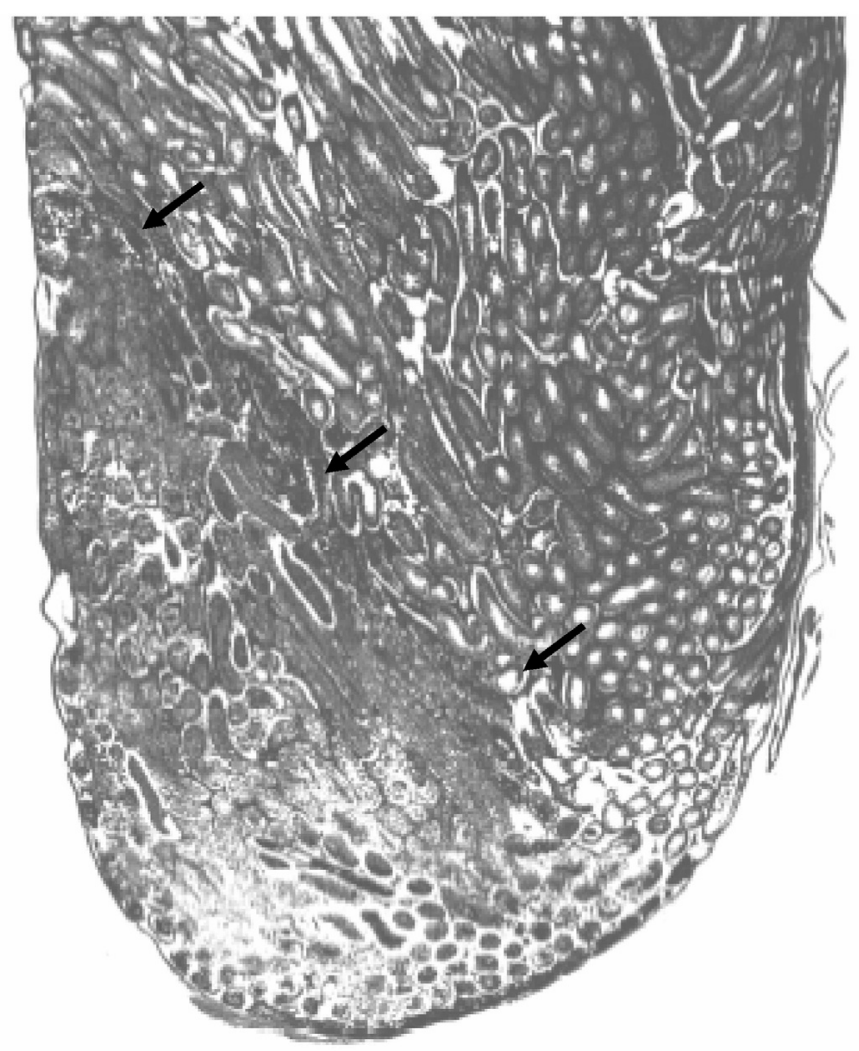

Photo 2. Microphotograph of longitudinal section of the testis after hCG treatment. The frontal lower part of the testis (arrows) shows necrotic area 2 days after s.c. $2000 \mathrm{IU} / \mathrm{kg}$ hCG dosing; the upper part shows no abnormality. H-E staining (by Chatani, 1996). 
Possible mechanism for testicular focal necrosis induced by hCG in rats.

testis where the Leydig cells were ablated by EDS treatment. In the F344 strain of rats, Leydig cell tumor occurs spontaneously by aging in very high incidence (Goodman et al., 1979; Chatani et al., 1990), and testicular tissues massively substituted by Leydig cell tumor showed focal or entire necrosis of tumor mass after hCG treatment in the present experiment. The Leydig cells probably maintain the ability to produce a sufficient level of $\mathrm{PG}$ in response to gonadotropin after tumorigenesis of the cells. These 2 experiments suggested that Leydig cells, at least at the adult age, have a potential to produce PG in response to hCG or luteinizing hormone-like gonadotropin.

The area of the necrosis produced by the hCG treatment was restricted in the frontal lower part of the testis (FLPT); while other areas of the testis showed no lesions. Histopathology showed that appearance of multinucleated giant cells in the seminiferous epithelia and interstitial neutrophil infiltration in the degenerative or necrotic tissues resembled the ischemic changes caused by a temporary ligation of the testicular artery (Oettlé and Harrison, 1950), and the seminiferous epithelial cells adjoining the intratesticular arterioles showed milder changes than those far from the arterioles (Chatani, 1996). The data by van Vliet et al. (1988) also suggested the restricted testicular changes induced by hCG treatment were probably caused by focal ischemia. In the present experiment, the FLPT where necrosis would occur 2 days after the hCG treatment was not stained as blue after an infusion of a blue dye solution into the extramural testicular arteries $6 \mathrm{hr}$ after the s.c. treatment of hCG, while other parts such as the upper part stained blue. It was unlikely that exudation of the dye through the testicular arterial wall to

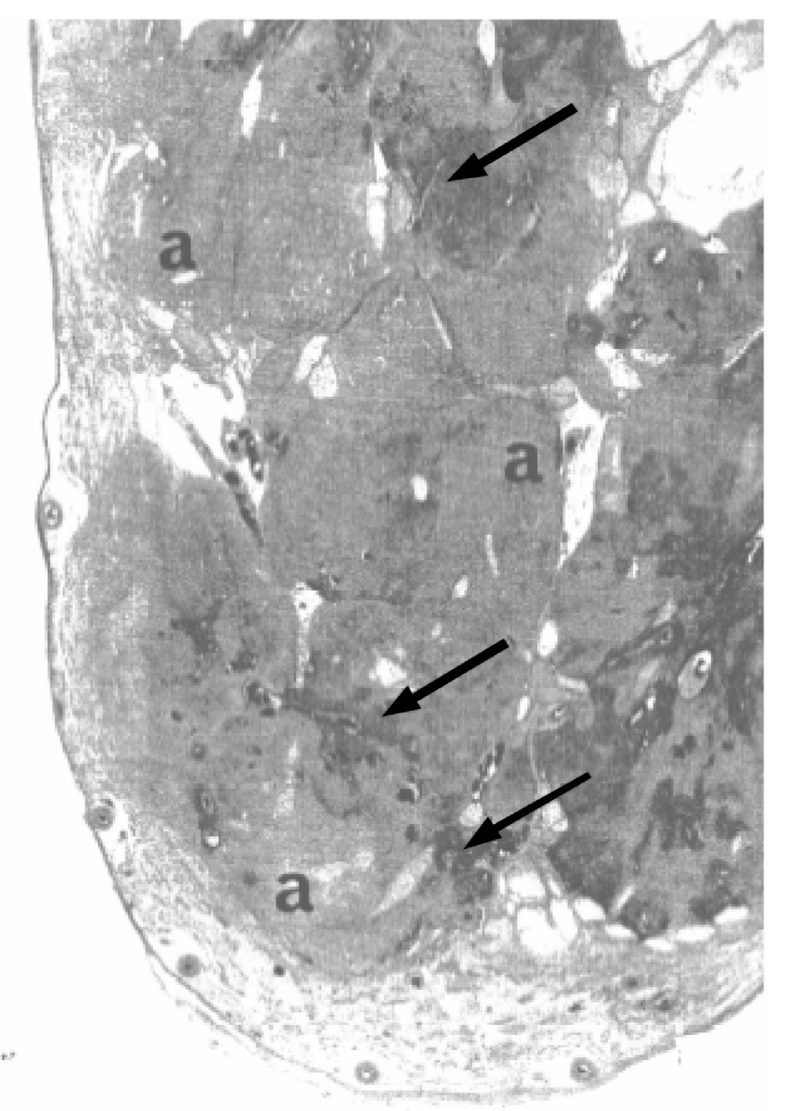

Photo 3. Microphotograph of longitudinal section of the testis occupied with massive Leydig cell tumors 2 days after s.c. 2000 $\mathrm{IU} / \mathrm{kg}$ hCG dosing. The tumor cell area shows massive necrosis (a) except for a small area (arrow). 


\section{F. CHATANI}

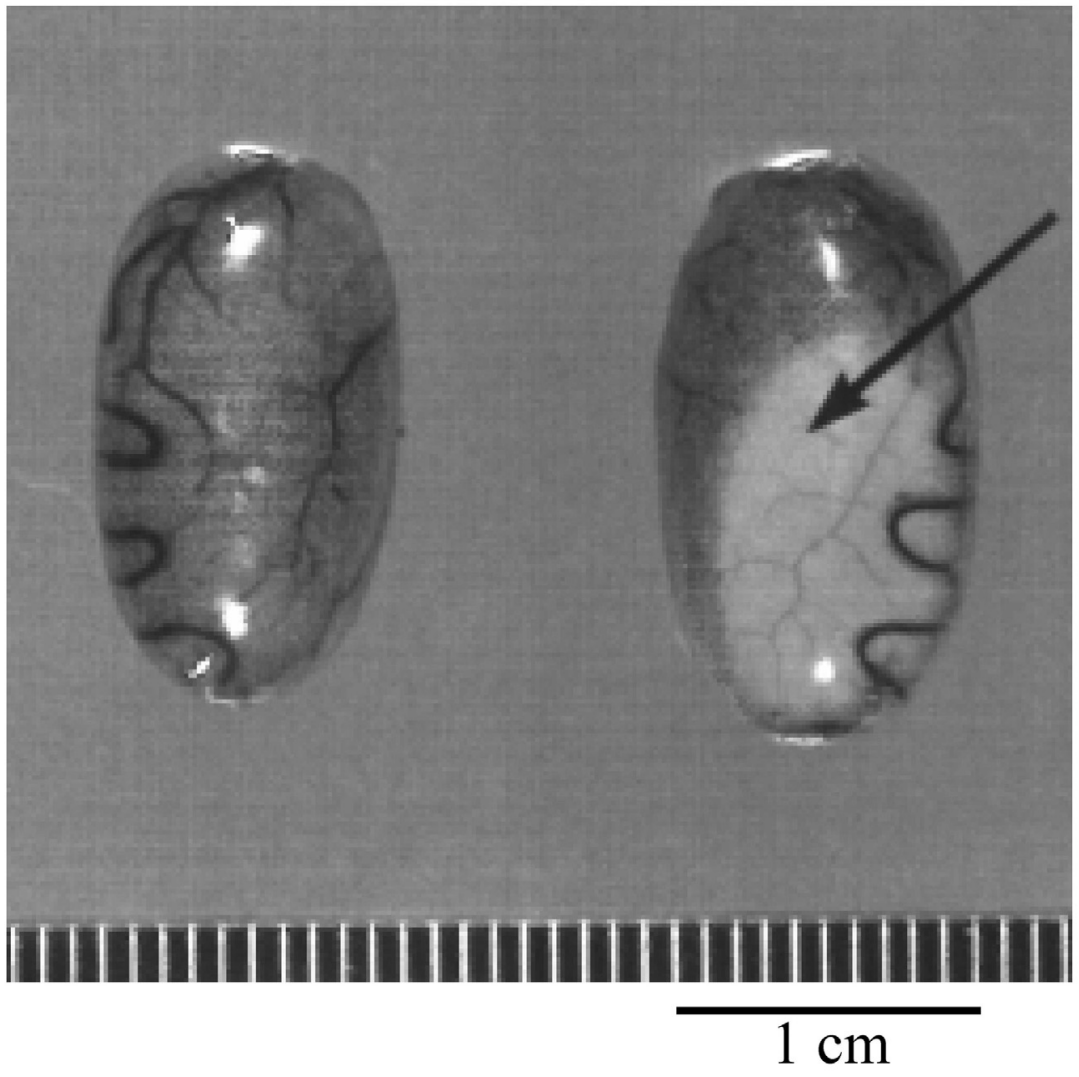

Photo 4. Macroscopic picture of the testis after an intra-arterial injection of blue dye 6 $\mathrm{hr}$ after s.c. $2000 \mathrm{IU} / \mathrm{kg} \mathrm{hCG}$ dosing. The upper part of the testis (right) is stained blue (gray in picture); the frontal lower part is stained less (arrow), suggesting an arterial obstruction in the lower part. The left is the control testis without hCG dosing.

\section{testicular blood flow}

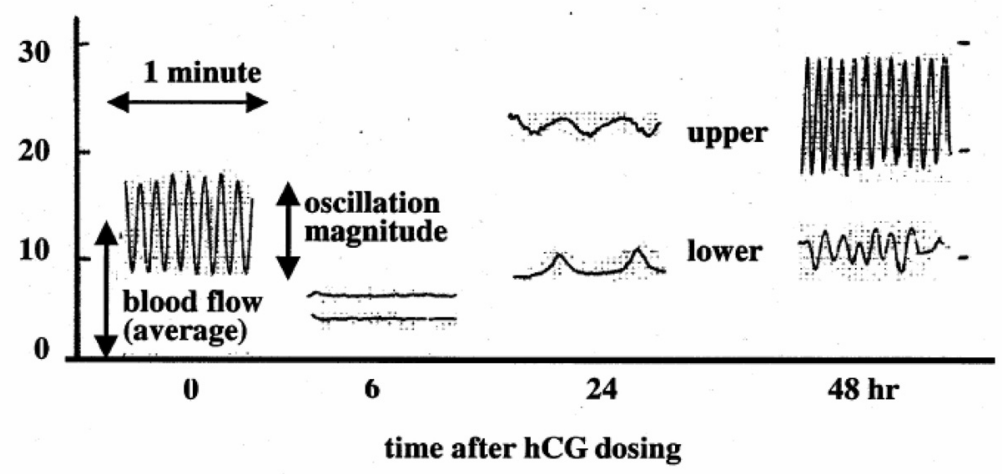

Fig. 3. Pulsatile blood flow chart at the upper and lower part of the testis 0,6 , 24 and $48 \mathrm{hr}$ after s.c. $2000 \mathrm{IU} / \mathrm{kg}$ hCG dosing. Representative charts are shown. Normal testis showed 8 pulsatile cycle/min $(0 \mathrm{hr})$. By hCG treatment, pulsatile pattern disappeared completely (oscillation magnitude $=0$ ) at $6 \mathrm{hr}$, an irregular pattern appeared at $24 \mathrm{hr}$, and regular and irregular patterns at $48 \mathrm{hr}$ at the upper and lower part, respectively. 
Possible mechanism for testicular focal necrosis induced by hCG in rats.

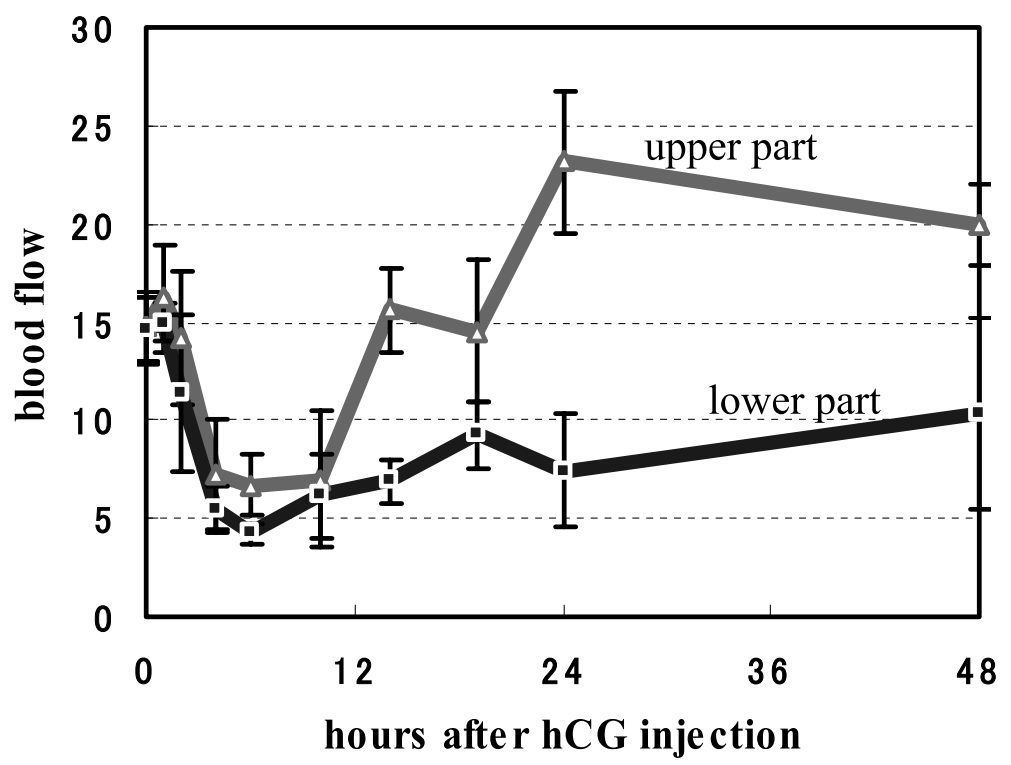

Fig. 4. Blood flow at the upper and lower part of the testis after s.c. $2000 \mathrm{IU} /$ $\mathrm{kg} \mathrm{hCG} \mathrm{dosing}$. The mean and S.D. is shown $(\mathrm{n}=3)$. hCG treatment reduced the blood flow and the flow at the upper part recovered earlier; the lower part showed a persistent low level.

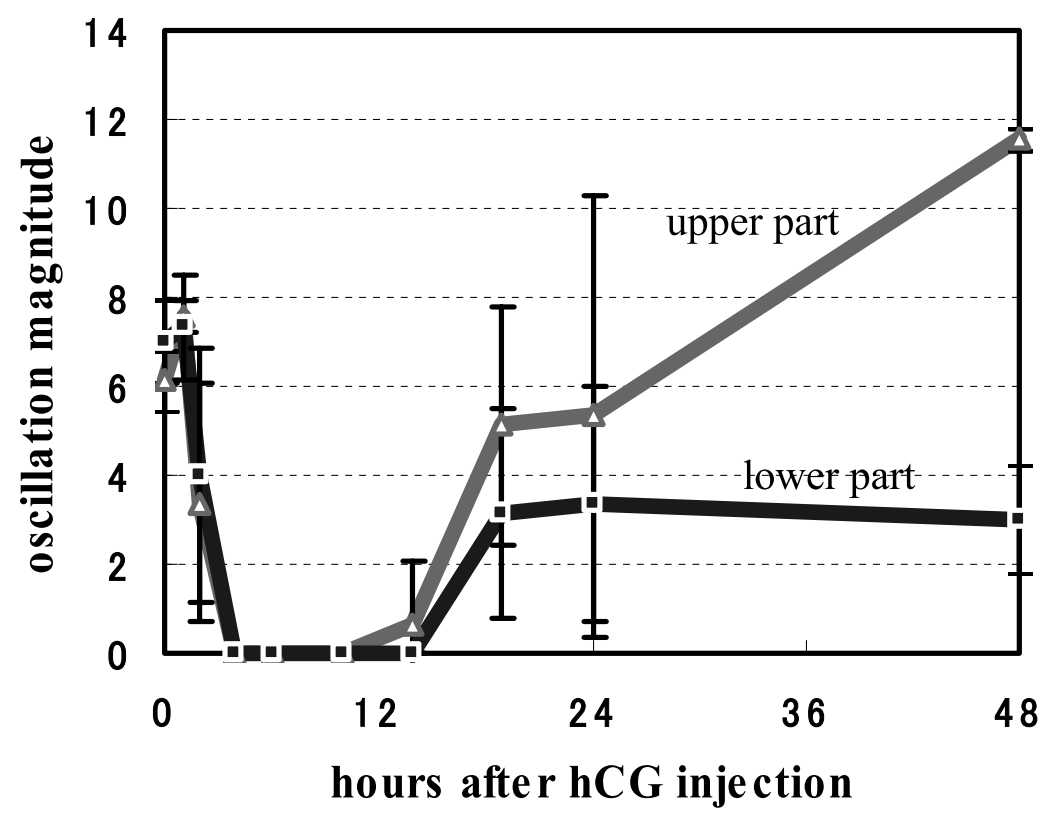

Fig. 5. Oscillation magnitude of blood flow at the upper and lower part of the testis after s.c. $2000 \mathrm{IU} / \mathrm{kg}$ hCG dosing. The mean and S.D. is shown $(n=3)$. The pulsatile oscillation disappeared completely (oscillation magnitude $=0$ ) for $10 \mathrm{hr}$ in both parts, and reappeared thereafter with a half-magnitude in the lower part. 
the interstitial tissue affected the observation of the distribution of the blue-staining on the testis because the gross observation was conducted within a very short time $(1 \mathrm{~min})$ after the dye injection to the artery. This suggests a dramatic decrease in the blood flow at the FLPT by hCG treatment. The silicon rubber template experiment also suggested a local contraction of the arteries. Arterial thrombosis is unlikely to account for the decrease in the blood flow because anticoagulant treatments such as heparin or an inhibitor for platelet activating factor failed to suppress the hCG-induced necrosis (Chatani, unpublished observations). A contraction of the arteries in the FLPT for more than $12 \mathrm{hr}$ is considered necessary for induction of the necrotic change, because a quicker recovery from the reduced blood flow in the upper part induced no necrosis. It is still not clear whether both intratesticular proximal arteries and arterioles/capillaries (Setchell, 1970) in the FLPT contracted simultaneously or not. The higher the dosage of hCG, the higher the necrosis score, suggesting that a large amount of PG can make the proximal arteries contract for a long period.

It was expected that testicular blood flow could decrease to nearly zero only in the FLPT but not at the upper part; however, the present laser Doppler flowmetry revealed that the blood flow decreased simultaneously in both the upper and lower parts of the testis to approximately $1 / 4-1 / 2$ of the control level with a disappearance of the rhythmical oscillation at $6 \mathrm{hr}$ after hCG treatment. The recovery of the flow and oscillation took longer in the lower part compared to the upper part. This difference in the duration of the reduction in blood flow between the lower and upper parts may contribute to the presence and absence of necrotic change. The present blood flow measurements were conducted using a probe which could sense approximately $1 \mathrm{~mm}$ beneath the testicular surface, and there still remains the possibility that the arteries/arterioles deeper in the testis (2-4 $\mathrm{mm}$ ) in the upper and lower testicular part showed more prominent differences in the blood flow. The reason for the discrepancy between the blood flow data and blue dye data is not clear yet. Reduction of the testicular blood flow and disappearance of the oscillation after an hCG treatment was reported by Widmark et al. (1986) without a description of the testicular part for the flow measurement. Intratesticular injection of $\mathrm{PGF}_{2 \alpha}$ or $\mathrm{PGE}_{2}$ into either upper, middle or lower part induced necrosis only in the FLPT but not in the upper part (data not shown). It can be speculated that these regional differences in the flow change might be due to differences in $\mathrm{PG}$ receptor densities and affinity on the intratesticular arterial wall or coupling of the receptor to internal messenger systems to cause contractions, and these might vary across strains and age of rats.

Similar mechanisms may be involved in the case of LH-RH agonist treatment via an elevation of plasma LH level. The contraction of the testicular artery by hCG may be a exaggerated effect of the testicular PGs. PGs were well known as a vessel-contractor or -dilator; however, they are also speculated to play roles in the metabolism of testosterone to dihydroxytestosterone by $5 \alpha$-reductase (Sawada et al., 1998) and to be potential mediators for the endocrine down-regulation and the phenomenon of desensitization (Haour et al., 1982). If similar necrotic or degenerative lesions occur in the FLPT in any toxicology studies for chemicals, these gonadotropin- or PG-mediated focal ischemia could be speculated to function as a mechanism of the occurrence of the lesions.

In summary, these data lead to the conclusion that the unique distribution of necrosis seen in the rat testis after high-dose hCG exposure is due to 1) increased de novo synthesis of PG by the Leydig cells; 2) PGinduced contraction of the interstitial arteries serving the lower part of the testis; and 3) consequent ischemia and massive cell death.

\section{ACKNOWLEDGMENT}

The author thanks Takako Iwachido and Masami Aoki for their pathologic technical assistance and also Drs. Robert E. Chapin and Eric J. F. Spicer for reviewing and correcting the manuscript.

\section{REFERENCES}

Ashida, Y., Saijo, T., Kuriki, H., Makino, H., Terao, S. and Maki, Y. (1983): Pharmacological profile of AA-861, a 5-lipoxygenase inhibitor, Prostaglandins, 26, 955-972.

Chan, C.-C., Boyce, S., Brideau, S., Charleson, W., Cromlish, D., Ethier, D., Evams, J., FordHutchinson, M.J., Forrest, J.Y., Gauthier, J.Y., Gordon, R., Gresser, M., Guay, J., Kargman, S., Kennedy, B., Leblanc, Y., Leger, S., Mancini, J., O’Neill, G.P., Ouellet, M., Patrick, D., Percival, M.D., Perrier, H., Prasit, P., Rodger, I., Tagari, P., Therien, M., Vickers, P., Visco, D., Wang, Z., Webb, J., Wong, E., Xu, L.-J., Young, R.N., Zamboni, R. and Riendeau, D. (1999): Rofexob [Vioxx, MK-0966; 4-(4'-methylsulfonylphe- 
Possible mechanism for testicular focal necrosis induced by hCG in rats.

nyl)-3-phenyl-2-(5H)-furanone]: a potent and orally active cyclooxygenase- 2 inhibitor. Pharmacological and biochemical profiles. J. Pharmacol. Exp. Ther., 290, 551-560.

Chatani, F., Nonoyama, T., Sudo, K., Miyajima, H., Takeyama, M., Takatsuka, D., Mori, H. and Matsumoto, K. (1990): Stimulatory effect of luteinizing hormone on the development and maintenance of $5 \alpha$-reduced steroid-producing testicular interstitial cell tumors in Fischer 344 rats. Anticancer Res., 10, 337-342.

Chatani, F. (1996): Testicular necrosis induced by hCG in rats - time-course and age- and strain differences - J. Toxicol. Pathol., 9, 369-379.

Goodman, D.G., Ward, J.M., Squire, R.A., Chu, K.C. and Linhart, M.S. (1979): Neoplastic and nonneoplastic lesions in aging F344 rats. Toxicol. Appl. Pharmacol., 48, 237-248.

Haour, F., Kouznetzova, B., Dray, F. and Saez, J.M. (1979): hCG-induced prostaglandin E2 and $F_{2 \alpha}$ release in adult rat testis: Role in Leydig cell desensitization to hCG. Life Sci., 24, 21512158.

Haour, F., Dray, F. and Mather, J.P. (1982) : In vivo and in vitro response of Leydig cells to acute stimulation by hCG. Ann. N.Y. Acad. Sci., 383, 231248.

Imura, Y., Terashita, Z., Shibouta, Y. and Nishikawa, K. (1988): The thromboxane $A_{2}$ /prostaglandin endoperoxide receptor antagonist activity of CV-4151, a thromboxane $A_{2}$ synthetase inhibitor. Eur. J. Pharmacol., 147, 359-365.

Imura, Y., Terashita, Z., Shibouta, Y., Inada, Y. and
Nishikawa, K. (1990): Antagonistic action of AA-2414 on thromboxane $\mathrm{A}_{2}$ /prostaglandin endoperoxide receptor in platelets and blood vessels. Jpn. J. Pharmacol., 52, 35-43.

Morris, I.D., Phillips, D.M. and Bardin, C.W. (1987): Ethylene dimethanesulphonate destroys Leydig cells in the rat testis. Endocrinology, 118, 709719.

Oettlé, A.G. and Harrison, R.G. (1950): The histological changes produced in the rat testis by temporary and permanent occulusion of the testicular artery. J. Path. Bact., 64, 273-297.

Sawada, T., Uemura, K., Tamada, H., Inaba, T. and Mori, J. (1998): Effects of oxytocin and prostaglandin $\mathrm{F}_{2 \alpha}$ on androgen production of adult rat testis in vivo. Prostagl. Lipid Mediat., 55, 121126.

Setchell, B.P. (1970): Testicular blood supply, lymphatic drainage, and secretion of fluid. In The Testis (Johnson, A.D., Gomes, W.R. and Vandemark, N.L., eds.), vol. 1, p120, Academic Press.

van Vliet, J., Rommerts, F.F.G., de Rooij, D.G., Buwalda, G. and Wensing, C.J.G. (1988): Reduction of testicular blood flow and focal degeneration of tissue in the rat after administration of human chorionic gonadotrophin. J. Endocr., 117, 51-57.

Widmark, A., Damber, J.-E. and Bergh, A. (1986): Relationship between human chorionic gonadotrophin-induced changes in testicular microcirculation and the formation of testicular interstitial fluid. J. Endocr., 109, 419-425. 